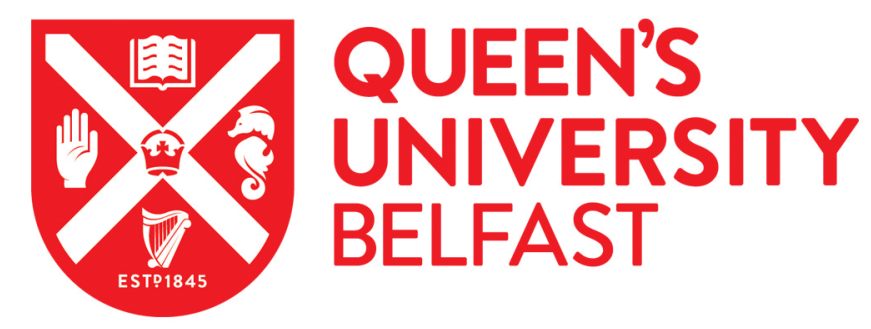

\title{
Considering axiological integrity: a methodological analysis of qualitative evidence syntheses, and its implications for health professions education
}

Kelly, M., Ellaway, R. H., Reid, H., Ganshorn, H., Yardley, S., Bennett, D., \& Dornan, T. (2018). Considering axiological integrity: a methodological analysis of qualitative evidence syntheses, and its implications for health professions education. Advances in Health Sciences Education : Theory and Practice, 23, 831.

https://doi.org/10.1007/s10459-018-9829-y

Published in:

Advances in Health Sciences Education : Theory and Practice

Document Version:

Peer reviewed version

Queen's University Belfast - Research Portal:

Link to publication record in Queen's University Belfast Research Portal

Publisher rights

(c) 2018 Springer Science+Business Media B.V., part of Springer Nature. This work is made available online in accordance with the publisher's policies. Please refer to any applicable terms of use of the publisher.

\section{General rights}

Copyright for the publications made accessible via the Queen's University Belfast Research Portal is retained by the author(s) and / or other copyright owners and it is a condition of accessing these publications that users recognise and abide by the legal requirements associated with these rights.

\section{Take down policy}

The Research Portal is Queen's institutional repository that provides access to Queen's research output. Every effort has been made to ensure that content in the Research Portal does not infringe any person's rights, or applicable UK laws. If you discover content in the

Research Portal that you believe breaches copyright or violates any law, please contact openaccess@qub.ac.uk. 
Considering axiological integrity: a methodological analysis

Considering axiological integrity: a methodological analysis of qualitative evidence syntheses, and its implications for health professions education

Martina Kelly ${ }^{1}$, Rachel H. Ellaway ${ }^{1}$, Helen Reid ${ }^{4}$ Heather Ganshorn ${ }^{1}$, Sarah Yardley ${ }^{2}$, Deirdre Bennett ${ }^{3}$, Tim Dornan ${ }^{4}$

${ }^{1}$ University of Calgary, Canada, ${ }^{2}$ Central \& North West London NHS Foundation Trust, UK, ${ }^{3}$ University

College Cork, Ireland, ${ }^{4}$ Queen's University, Belfast, Northern Ireland

Martina Kelly

Department of Undergraduate Family Medicine

University of Calgary

3330 Hospital Drive

Calgary, Alberta, T2N 4N1

Canada

Tel: $403-210-7347$

Fax: $403-210-9746$

Email: makelly@ucalgary.ca 
Considering axiological integrity: a methodological analysis

\section{Abstract}

Qualitative evidence synthesis (QES) is a suite of methodologies that combine qualitative techniques with the synthesis of qualitative knowledge. They are particularly suited to medical education as these approaches pool findings from original qualitative studies, whilst paying attention to context and theoretical development. Although increasingly sophisticated use is being made of qualitative primary research methodologies in health professions education (HPE) the use of secondary qualitative reviews in HPE remains underdeveloped. This study examined QES methods applied to clinical humanism in healthcare as a way of advancing thinking around the use of QES in HPE in general. A systematic search strategy identified 49 reviews that fulfilled the inclusion criteria. Meta-study was used to develop an analytic summary of methodological characteristics, the role of theory, and the synthetic processes used in QES reviews. Fifteen reviews used a defined methodology, and 17 clearly explained the processes that led from data extraction to synthesis. Eight reviews adopted a specific theoretical perspective. Authors rarely described their reflexive relationship with their data. Epistemological positions tended to be implied rather than explicit. Twenty-five reviews included some form of quality appraisal, although it was often unclear how authors acted on its results. Reviewers under-reported qualitative approaches in their review methodologies, and tended to focus on elements such as systematicity and checklist quality appraisal that were more germane to quantitative evidence synthesis. A core concern was that the axiological (value) dimensions of the source materials were rarely considered let alone accommodated in the synthesis techniques used. QES can be used in HPE research but only with careful attention to maintaining axiological integrity.

Key Words: qualitative evidence synthesis, health professions education, values, axiological integrity, humanism 
Considering axiological integrity: a methodological analysis

\section{Introduction}

Qualitative evidence synthesis (QES) is 'any methodology whereby study findings are systematically interpreted through a series of expert judgments to represent the meaning of the collected work. In (QES), the findings of qualitative studies - and sometimes mixed-methods and quantitative research - are pooled' (Bearman \& Dawson, 2013). QES is an emergent field, which started in the 1990s, and has steadily grown since the 2000s. In 2007, a review of QES studies identified 42 papers, by 2012, this had increased to 81 (Dixon-Woods, Booth, \& Sutton, 2007; Hannes \& Macaitis, 2012). QES is particularly well suited to health profession education (HPE) research as it allows us to synthesize findings from primary qualitative studies, which are commonly conducted in HPE. QES thus enables HPE researchers to extend review questions beyond ones of effectiveness (Bondas \& Hall, 2007)and integrate research from such disparate qualitative traditions as ethnography, grounded theory, and phenomenology. QES methodologies identify consensus, generate hypotheses, and investigate contradictions between studies, to go beyond and behind original studies to develop theories (Bondas \& Hall, 2007) and inform new avenues for future research. QES now plays an important role in reviews conducted by the Cochrane Collaboration, (Hannes, Booth, Harris, \& Noyes, 2013) the US Agency for Healthcare Research and Quality (AHRQ), and the UK National Institute for Heath and Clinical Excellence (NICE). To date, QES methodologies have not been widely used in HPE and qualitative studies are frequently excluded from many conventional systematic reviews. The few reviews that include primary qualitative data tend to thematic analysis (Cowen, Kaufman, \& Schoenherr, 2016; Sulzer, Feinstein, \& Wendland, 2016), with limited adoption of the synthetic potential of qualitative evidence synthesis (QES).

One area particularly suited for examination with QES in HPE is humanism. Qualitative evidence is particularly suited to the study of humanism as it has its origins in research methods from the humanities and social sciences, and seeks to analyze the complexity of human phenomena in naturalistic settings and from a holistic perspective (The Joanna Briggs Institute, 2017). Investigators have made good use of qualitative primary research methodologies to clarify aspects of education that are laden with values such as the study of empathy, compassion and emotions, with a well-established literature in the medical humanities. As the literature base grows the opportunity and need for synthesis also grows, but traditional approaches to synthesizing humanistic evidence can be problematic in this regard because they cannot 
Considering axiological integrity: a methodological analysis

accommodate the values and emotions expressed in the source material considered. In short, values and emotions often do not survive evidence synthesis, thereby questioning the integrity of this kind of synthesis process for evidence that has a substantial values and emotions component. The ability to retain values and beliefs in QES has not been a significant part of its discourses, and, as a result, the applicability of QES to HPE literature in ways that retain value and belief systems in the review process remains unclear.

Given that there has been little formal use of QES in HPE (Bearman \& Dawson, 2013), and that much of the primary literature on professionalism, empathy, compassion, and other humanistic topics is value-rich, we set out to investigate how secondary researchers had synthesized conclusions from primary qualitative research in clinical humanism. We used clinical humanism, as a proxy topic for health professions education as it embodied the challenges of synthesizing the values inherent in primary qualitative research alongside its factual content. Our research question was: how has QES been used to transfer, translate, and/or synthesize qualitative findings derived from primary studies of clinical humanism?

\section{Methods}

Conceptual orientation: The ontological assumption of the study was that qualitative research is inherently axiological (Heron \& Reason, 1997). Axiology is the study of values (Pole, 1961). In qualitative research, consideration of axiology prompts the researcher to reflect on the intrinsic values inherent in a research question. This may include evidence on values (such as research into compassion or empathy in medical education), evidence that employs a values-based approach (such as research into social accountability or social justice issues), and evidence that is situated within a value-informed system (such as lobbying for educational reform). Axiological integrity is the ability to retain values in transferring, translating, or synthesizing axiological evidence. The values need not be adopted or endorsed in the resulting work but they should not be lost in translation. In knowledge synthesis axiological integrity is retained where values, beliefs, and emotions in source materials contribute to the synthesis.

Our methodological assumption was that QES procedures should consider the axiological perspectives of the studies they review (Biddle \& Schafft, 2015) as well as their epistemologies and ontologies. This was our working definition of axiological integrity. 
Considering axiological integrity: a methodological analysis

Definition of humanism: For the purposes of this study, we used the definition of humanism as 'an ethical system, which emphasizes human values and the personal worth of each individual, as well as concern for the dignity and freedom of humankind.'(U.S. National Library of Medicine, 2015). Humanism has often been closely associated with professionalism as many of its values map to competencies of professionalism (Cohen, 2007; Martimianakis et al., 2015). Humanistic values, such as compassion, fidelity, respect, and virtue (Rogers \& Coutts, 2000), are notoriously hard to measure. This is well illustrated by the ongoing debates about how empathy should be defined (Pedersen, 2009; Smajdor, Stöckl, \& Salter, 2011) despite attempts (both primary and secondary) to resolve it (Hemmerdinger, Stoddart, \& Lilford, 2007).

Methodology: Tertiary qualitative research (the synthesis or analysis of studies that are themselves syntheses) is, as yet, a relatively underdeveloped field. We therefore considered different secondary QES methodologies in designing the study. The methodology that came closest to meeting our needs was meta-study, a constructivist form of QES (Paterson, Canam, Thorne, \& Jillings, 2001), which acknowledges the inextricable link between method, theory, and the subject matter of an evidence review (Paterson et al., 2001). By using meta-study 'diagnostically' (Frost, Garside, Cooper, \& Britten, 2016) we aimed to draw firm conclusions about methodological aspects of QES in clinical humanism and gain insights into each study's axiological integrity. From this, we sought to glean lessons that could be applied in QES in HPE research. Throughout this article, we have used the term 'methodology' to mean that an explicit epistemological position guided analytical procedures and supported inferences that researchers drew from their procedures. When authors took no conscious epistemological stance, we used the term 'methods'.

Team membership: The research team comprised five physician researchers, a health sciences librarian (HG) and a social scientist (RE). Team members came from Canada (MK, HG, RE), the UK (SY, HR, TD) and the Republic of Ireland (DB). All of the team were experienced in qualitative health research, including discourse analysis, phenomenology, and critical review. 
Considering axiological integrity: a methodological analysis

Identification of relevant studies: MK and a research librarian (HG) conducted a preliminary search in MEDLINE, refined it, and carried out additional searches based on the revised strategy in MEDLINE, the Cumulative Index to Nursing and Allied Health Literature (CINAHL), ProQuest Dissertations and Theses, Psyclnfo, SocINDEX, the Joanna Briggs Institute Database of Systematic Reviews and Implementation Reports, and the Cochrane Database of Systematic Reviews. We devised our search syntax by separating the research question into three components: 'qualitative review', 'humanism' and 'healthcare' (Figure 1). Appendix A contains the full MEDLINE and CINAHL search strategies. Database results were imported into EndNote bibliographic software (Thomson Reuters, U.S.A, version 7.7.1) and duplicates deleted. We manually followed up on reference lists to identify additional citations, and hand-searched journals likely to publish qualitative synthesis (Journal of Advanced Nursing, Qualitative Health Research, 2012-2015).

Inclusion and exclusion criteria: We searched for systematic reviews of qualitative primary studies that had examined humanistic healthcare. We started by adopting the MeSH definition of humanism and further clarified our understanding of the term by reading highly cited articles on humanism in healthcare (identified by Google Scholar \& PubMed). Although humanism and humanities were sometimes used interchangeably, we excluded papers on humanities subjects that were not specifically relevant to clinical humanism. Given the tensions between humanism and professionalism in medical education (Cohen, 2007; Goldberg, 2008) and the resulting difficulties surrounding the use of these concepts, we elected not to use professionalism as a specific search term, although, if a review contained information on both professionalism and humanism, we included it. We elected not to use 'spirituality', another humanismrelated concept, as a search term for similar reasons. We included articles in any language, unlimited by year of publication that met the inclusion criteria mentioned earlier. Studies often used qualitative techniques within mixed methods designs. We included these if the contribution of the qualitative studies cited within them was identifiable.

Selection of relevant articles: MK assessed all titles and abstracts. She randomly assigned abstracts for team members, working in pairs, to screen. To identify relevant studies, members of each pair first reviewed abstracts individually and then together. They discussed to what extent and why they agreed on 
Considering axiological integrity: a methodological analysis

fulfillment of the inclusion/exclusion criteria. When they could not agree, they brought the question to the full group for discussion and a final decision by consensus.

Quality appraisal: We piloted two QA tools: the Revised Assessment of Multiple Systematic Reviews(RAMSTAR) (Kung et al., 2010; Pearce et al., 2015), and Glassick's expanded definitions of scholarship (Glassick, Huber, Maeroff, \& Boyer, 1997). R-AMSTAR was devised to quantify the quality of systematic reviews. In the absence of published standards for systematically appraising quality in QES, it was adapted by Pearce et al (Pearce et al., 2015) to quality appraise qualitative systematic reviews. It consists of eleven questions, scored numerically to give a final score, with higher scores indicting higher review quality. One question reviews the comprehensiveness of a literature search, which includes searching across more than one database, inclusion of key terms, details of the search strategy and supplemental searching such as hand-searching, contacting experts in the field and reviewing references of identified studies. In contrast, the Glassick model is based on six criteria for scholarly work; clear goals, adequate preparation, appropriate methods, significant results, effective presentation and reflective critique (Glassick et al., 1997).

We found that many R-AMSTAR items were not relevant to this study, whereas the open-ended nature of Glassick's model was a better fit to the variety of QES approaches we encountered. We therefore developed and piloted a quality appraisal form based on Glassick's model and incorporated some of the search strategies described in R-AMSTAR. Rather than excluding studies on the basis of rigor, we identified examples of high and poorer quality reviews, to inform our synthesis. We also gathered information about whether and how QES researchers included quality appraisal for further analysis.

Data extraction: All members of the study team piloted and refined a data extraction form based on metastudy methodology (Paterson et al., 2001). This considered data at three levels: meta-method, metatheory and meta-analysis. We recorded details of the methodology of each review and how it was implemented. To identify if and how theory informed the review, we categorized and recorded the explicit or implicit theoretical stance of each article using a published taxonomy of epistemological stances (Thomas \& Harden, 2008). 
Considering axiological integrity: a methodological analysis

Analysis and synthesis: We conducted (qualitative) meta-analysis focused on determining how QES methodologies had extended the understanding of clinical humanism in healthcare beyond the individual studies they included (rather than on the humanistic subject matter contained in the QES articles). An overview of our data extraction items is provided in Table 1. We conducted our synthesis in parallel with data extraction. As we read and re-read the reviews, we worked in pairs to extract data and appraise the papers, keeping reflective notes on our observations and interpretations. On occasion, if pairs did not agree on an interpretation, they first discussed their concerns with MK and then, if necessary, with the whole team. The entire data-set was tabulated in MS Excel and summary statistics generated on categorical data. MK \& HR analyzed qualitative data in text files thematically and shared initial interpretations with TD and RE. The team re-examined the findings to look for patterns across the reviews, areas of resonance and dissonance, exemplar reviews, and key concepts. We developed our final interpretations by repeatedly examining and discussing the findings. We maintained an audit trail throughout the research process.

Reflexivity: Recognizing that the constructivist concept of reflexivity is progressively gaining ground over triangulation, member checking, emergence, saturation, and other traditional, post-positivist arbiters of qualitative rigor (Varpio, Ajjawi, Monrouxe, O'brien, \& Rees, 2017), we maintained reflexivity by discussing our subject positions towards the topic and subjective responses to the articles we read, and explored our different subject positions, first within coding pairs and then within the whole research team.

Reporting of findings: The results section below reports our identification of how QES publications transferred, translated, or synthesized qualitative findings derived from primary research. Its final subsection synthesizes conclusions from the three previous subsections. The Discussion section meets the research aim of appraising the sensitivity of QES to values by linking the results to the concept of axiological integrity.

\section{Results}

The final dataset consisted of 49 reviews (Figure 2) published between 1996 and 2016. Fourteen reviews were written by single authors and one author contributed six reviews (Finfgeld-Connett). Most were conducted in the US $(n=15)$ or Scandinavia $(n=11)$. Some disciplinary fields were more represented than 
Considering axiological integrity: a methodological analysis

others, with clusters of activity in obstetrics and midwifery $(n=9)$, mental health $(n=9)$, palliative care $(n=8)$, and elderly care $(n=7)$. Thirty studies were published in nursing journals. Twenty-five studies were exclusively qualitative and twenty were mixed methods studies. The number of studies included in the QES we reviewed ranged from 1 to 132 , with an average of 25 studies (median $=21$ ). Twenty-three reviews received funding $(47 \%)$.

\section{Meta method: analytical summary of methodological characteristics of QES reviews}

Searching, including, and excluding: More recent reviews tended to be more specific and systematic in their search criteria, often with more of a focus on exhaustive rather than exploratory searching. These more recent searches were also more likely to have been conducted by librarians, to have used clearly specified search terms, defined inclusion and exclusion criteria, and to have been conducted across multiple databases. In contrast, qualitative approaches to data gathering such as purposive and theoretical sampling, and searching to sufficiency, were seldom used, and novel search techniques, such as CLUSTER (Booth et al., 2013) or 'berry picking' (Bates, 1989), were not used at all. The trend towards systematicity was reflected in the near-ubiquitous use of PRISMA flow diagrams (from the time PRISMA reporting standard were published in 2009). Thirty-eight reviews included only primary qualitative studies, whilst 10 reviews included editorials, commentaries, or policy documents alongside empirical investigations.

Quality appraisal: We did not rank reviews based on quality appraisal but used our findings to sensitize us to overall review quality and the role of quality appraisal itself within QES. We found no discernable pattern in the way reviewers critically appraised primary studies. Just under half the reviews did not appraise the quality of the primary research they synthesized. Twenty-five appraised quality using CASP $(n=6)$ (Critical Appraisal Skills Programme (CASP), n.d.), the Joanna Briggs Institute appraisal instrument ( $n=4)$ (The Joanna Briggs Institute, 2014), Polit \& Beck's Inventory $(n=2)$ (Polit \& Beck, 2008), COREQ $(n=1)$, (Tong, Sainsbury, \& Craig, 2007), or other tools. Some reviewers excluded methodologically weak studies, others weighted the influence of studies according to their quality, while others included all studies irrespective of the appraisal they had done. Reviewers rarely justified how they had used (or not used) critical appraisal. 
Considering axiological integrity: a methodological analysis

Stated methodology: One third of reviews named a recognized methodology, most commonly metaethnography $(n=10)$. The remainder used contested, multiple definitions, e.g. meta-synthesis, phenomenological synthesis, or broad and non-specific labels, such as 'systematic review', or they did not name their methodology at all. When reviewers did specify their methodological position, they often failed to adopt its epistemological positioning - or any epistemological positioning. As a result, we can say that most reviews we considered used methods rather than methodologies.

\section{Meta-theory: analytical summary of the contribution of theory to QES reviews}

Use of theory to illuminate subject matter: Eight reviews used insights from theory to unify their review questions, methodologies, and findings into integrated wholes. A review of maternity care in different cultures, for instance, (Wikberg \& Bondas, 2010) drew on Eriksson's carative theory to guide the evidence synthesis with an explicit conceptualization of 'care'. Other authors who cited theories in their introduction or discussion sections did not use these theories to illuminate their findings, nor use the findings to illuminate the theories. Sixteen reviews, which did not take a theoretical position a priori, developed conceptual frameworks or theoretical models from their findings. The remainder were atheoretical. This meant that, while reporting improvements in clinical care, it was unclear what they meant by the term 'care'.

Use of theory to guide methods: We found that QES authors infrequently reported on their reflexive relationships with the data they analyzed, some did not even report their disciplinary backgrounds. They rarely took implicit epistemological positions, though their implicit positions were made apparent by the ways they problematized their topics, used theories to examine data, conducted their analyses and syntheses, reported findings, and drew inferences from their data. Table 2 maps these to a categorization of epistemological standpoints \{Barnett-Page, $2009 \# 1\}$. We found that implicit realist perspectives, predominantly critical realism, were the most common position taken $(n=32)$.

\section{Meta-analysis: analytical summary of analytic and synthetic processes of QES reviews} Most reviews reported using coding, categorizing, and organizing data thematically, with 17 of them providing details on how they did so. Most studies collated and condensed large volumes of data thematically and then reported their aggregated findings in the form of a structured overview of 
Considering axiological integrity: a methodological analysis

commonalities between studies. Disconfirmatory evidence, outliers, and other sources of variance were rarely discussed. When authors said they had translated studies, analyzed metaphors, identified lines of argument, or conducted refutational synthesis, it was often unclear how they had done so. Authors appeared to favor descriptive re-organizations of source material as opposed to seeking to answer novel research questions, detailed secondary analysis of primary materials and/or synthesis of novel or surprising insights gained from group analysis of data from a range of primary materials.

\section{Our meta-synthesis of review findings}

We interpret the preceding overview of method, theory, and analysis as evidence that a realist (pragmatic positivist) epistemology tacitly dominated approaches to QES of clinical humanism. Reviewers systematically collected data, constructed searches, reported their syntaxes, defined inclusion and exclusion criteria, reported selection processes in PRISMA diagrams, applied appraisal standards defined by quality appraisal tools, and thematically described the findings of primary research. They did so in order to make their findings reliably representative (as defined by current norms within the domain of medical sciences) of available evidence. This adheres to widely held standards of rigor in evidence synthesis. We found less evidence, however, of theoretically informed, engagement with informative (rather than representative) data (which would typify a qualitative stance). One exception to this is given by Entwistle (Entwistle, Firnigl, Ryan, Francis, \& Kinghorn, 2012), where the research team clarified different aspects of experience and then constructed a maximum variation sample to identify literature across diverse health services experiences. In contrast to the systematicity of their searching, reviewers often reported on and named methodologies inconsistently, and adhered weakly to the principles of those they had nominally adopted. Reviewers claiming to have conducted meta-ethnographies, for example, cited the seminal work of Noblit and Hare (who developed meta-ethnography), yet rarely detailed first, second, and third order constructs, which operationalize this approach. Authors often provided descriptive detail of primary studies but did not show how they generated valid inferences from the data they had extracted. Theory was integrated into study procedures somewhat haphazardly, and it rarely emerged from the processes of evidence synthesis.

In summary, we found that positivist norms and values dominated what was avowedly constructivist research. Reviewers rigorously dissected data into simpler parts and aggregated them into descriptive 
Considering axiological integrity: a methodological analysis

summaries but stopped short of synthesizing novel and informative insights from the evidence they had assembled.

\section{Discussion}

Principal findings and meaning: Our novel, tertiary research methodology has shown that the rigor of QES can be strengthened. We base this conclusion on findings from QES in clinical humanism, which we believe can proxy for topics in HPE more broadly. Whilst reviewers were typically systematic in assembling representative data, they were less systematic in drawing reflexively situated conclusions from those data. Reviewers made limited use of theory to inform their analytical procedures and to shed light on the primary data they had assembled. Some reviewers generated theories from the primary data but, when the reviews had taken no a priori theoretical stance, these were limited in their ability to advance wider understanding of their topics. Carter and Little defined good quality qualitative research as research that attends to epistemology, methodology and method and demonstrates internal consistency between them (Carter \& Little, 2007). Attention to internal consistency, they concluded, could transcend checklist definitions of external consistency and facilitate innovation and diversity (Carter \& Little, 2007). What we found was more a scholarship of precis than a scholarship of innovation. That the studies we reviewed failed to be 'greater than the sum of their parts' in this regard reflects Thorne et al.'s contention that that synthesis should be more than descriptive (Thorne, Jensen, Kearney, Noblit, \& Sandelowski, 2004). A specific focus on synthesizing the values and ideologies of primary sources in QES as well as their more descriptive features would seem to be an essential addition to this methodological discourse.

The heavy emphasis on systematicity indicates that principles of representativeness and reliability tend to dominate secondary research, even when synthesizing qualitative data. One reading of this is that realist principles are so dominant in the discourses of their field that reviewers consciously depart from constructivist methodologies in order to have their work taken seriously. Another is that being reflexive makes them uncomfortable so they default to realist objectivities. A final, and more optimistic, interpretation is that paradigm shifts take place slowly. We should not, therefore, be surprised that constructivist thinking is taking time to find its place in secondary qualitative research. 


\section{Considering axiological integrity: a methodological analysis}

There is little precedent for conducting a tertiary review of research methodologies and even less precedent for conducting a tertiary review of how values are translated in secondary research. We chose a value-laden topic (clinical humanism) with the aim of developing thinking about QES in HPE rather than being particularly concerned with the topic in and of itself. What we found was that reviewers defaulted to the implicit pragmatism of realist methods rather than embracing constructivist possibilities of qualitative research, even when the primary research had addressed such value-laden topics as compassion, fidelity, respect, and virtue. Axiological integrity, we suggest, currently remains an aspiration more than an evaluable reality in QES in clinical humanism, and as such, our conclusion is that QES in HPE will need to be attentive to axiological integrity to advance work in the field.

Strengths and Limitations: Given the very low formal uptake of QES methods in health professions education, our decision to use clinical humanism as a proxy for HPE, while strategically necessary, was a limitation in assessing the nature of practice in our own field. The issues we encountered and our findings should therefore be understood as a lesson for future practice rather than as correcting an extant problem in QES in HPE. Secondly, since we stepped outside realist assumptions in order to conduct this review, we would expect readers who adhere firmly to realist principles to consider it somewhat lacking. We argue that implicit colliding worldviews make this unsurprising but not necessarily a weakness. Nevertheless, this study has limitations, even judged by constructivist principles. Reflexive data analysis is only as valid as the perspectives of the review team. Our review team represented a range of views but included, for example, only two non-clinicians. It was made up of researchers who were more familiar with qualitative methodologies than quantitative methodologies. To minimize bias, we critically appraised and reflected on our interpretations to ensure our evaluations were neither unduly harsh nor lenient. It is entirely possible that a different team might have come to a different interpretation of the findings. There was no precedent, moreover, for appraising how reviewers translated values from primary into secondary research so we could draw only limited conclusions about axiological integrity. The diversity of material and methods we included within this study may have diluted its findings. Perhaps researchers examining more specific and demarcated topics or solely working within particular methodologies give more explicit rationales for their methodological choices. Maybe that was a price that had to be paid for the breadth of material on which our conclusions were based. Finally, some readers may find the overall tone of the review too critical. Our intention is not to disparage the research we considered. To the contrary, we 
Considering axiological integrity: a methodological analysis

interpret the shortcomings positively because they show a continued commitment to rigour, even when paradigmatic tensions are emerging. It is inevitable that reviewers will find shortcomings when they appraise, in hindsight, research published during a paradigm shift. The efforts of qualitative reviewers to bring about such a shift are to be welcomed and should spur other researchers to carry forward the research effort. In terms of strengths, while situating our study within existing QES discourses, we have taken a relatively novel approach that has included both conceptual and methodological innovations, and in doing so we hope to stimulate critical thinking and further developments both in QES and around the concept of axiological integrity.

Relationship to earlier publications: Booth has written extensively of the challenges of searching qualitative literature and compared exhaustive searching, common in quantitative review, with theorydriven approaches, which resemble maximum variation or sampling to saturation in primary qualitative research (Booth, 2016; Cooke, Smith, \& Booth, 2012; Papaioannou, Sutton, Carroll, Booth, \& Wong, 2010). Controversies surrounding quality appraisal such as balancing the benefits of including only highquality studies versus the risks of excluding illuminating findings of poorly conducted research have been written about before (Carroll \& Booth, 2015; Dixon-Woods et al., 2006; Hannes, 2011). Perhaps the most confusing aspect of QES relates to methods of synthesis; this confusion is exacerbated by its use of a bewildering array of terms, previously described as 'meta-madness' (Thorne et al., 2004). Our conclusion that qualitative synthesis lacks clarity is not new (France et al., 2014; Frost et al., 2016; Hannes \& Macaitis, 2012). What this study adds to earlier critiques of QES methodologies is to show that researchers struggle to synthesize meta-level conclusions, particularly when it comes to values.

Implications: The main implications of this review are focused on the research community. A fundamental strength of qualitative research is that it is generative. It develops new insights into human behavior within given contexts. Questions tend to be open-ended, methodologies are flexible, findings extend beyond thematic bunching to creating new meanings, presented in imaginative ways and enriched by contextual detail. Medical education, as a non-linear, organic field that brings together multiple methodological and philosophical approaches (Ellaway et al., 2016), is well placed to move QES beyond 'state of the nation reporting' to effecting conceptual change. The professionalism agenda in health professions education makes it important for reviewers to be mindful of context and, in particular, to advance our understanding 
Considering axiological integrity: a methodological analysis

of professional values in particular contexts and how they are translated or synthesized. This calls for further work to make axiological integrity a more explicit feature of QES. One simple way to do this would be to go beyond Carter and Little's (2007) advocacy for epistemology and pay greater attention to ontology - theories of the nature of being - on which values ultimately depend. However, we also acknowledge that synthesis is an intrinsically reductionist process and not all contextual or axiological details can realistically be preserved intact. Pursuing axiological integrity is, like synthesis in general, about drawing out and highlighting the important and germane values and value systems, and is therefore a matter of judgment rather than an absolute requirement.

Conclusion: QES methodologies are gaining a foothold in the field of clinical humanism, but there is potential for them to contribute much more (Frost et al., 2016), particularly in and around issues of axiological integrity. From this we conclude that, while QES shows great potential for being used in HPE, scholars need to be mindful of axiological integrity at all stages in undertaking a QES review. Rather than condemning colleagues brave enough to embark on the onerous journey of QES, our findings suggest ways they could enhance the rigour and richness of their work. Central to maintaining axiological integrity is the need to maintain principles of qualitative research by making clearly justified and transparent use of methodologies, paying greater attention to reviewer positionalities, clearly framing the epistemological stances of their research questions, and grounding their work in theory. In the words of TS Elliot "Between the idea,/And the reality,/Between the motion,/And the act,/Falls the Shadow". QES can fall victim, like the Hollow Men of Elliot's poem, to being caught in a half-world, where the dominant shadow of positivist thinking eclipses the generative, theoretically rich potential of QES. We hope, through this study, to establish the need for these principles in QES in HPE and thereby to frame axiological integrity as a key issue in tertiary research in our field.

\section{Funding}

The author(s) disclosed receipt of the following financial support for the research, authorship, and/or publication of this article: This project was made possible by award of a "Mapping the Landscape, Journeying Together" grant from the Arnold P. Gold Foundation Research Institute. 


\section{Appendix A. Search Syntax Medline and CINAHL}

Ovid MEDLINE search strategy

1. $\exp$ Meta-Analysis as Topic/

2. exp "Review Literature as Topic"/

3. systematic review*.mp. [mp=title, abstract, original title, name of substance word, subject heading word, keyword heading word, protocol supplementary concept word, rare disease supplementary concept word, unique identifier]

4. 1 or 2 or 3

5. (qualitative or interpretive or ethnograph*).mp.

6. 4 and 5

7. (critical interpretative synthes\#s or ecological triangulation* or grounded formal theor* or metaethnograph* or meta-interpret* or meta-narrative* or meta-stud* or meta-summar* or meta-synthes\#s or qualitative meta-analys\#s or qualitative synthes\#s or textual narrative synthes\#s or thematic synthes\#s).mp.

8. 6 or 7

9. (respect* or trust* or kindness or compassion* or altruis* or empath* or humanis ${ }^{*}$ or humane or presence).mp.

10. exp Humanism/

11. exp Empathy/

12. exp Trust/

13. 9 or 10 or 11 or 12

14. 8 and 13

\section{CINAHL Search History}

\# Query

S12 (S1 OR S2 OR S3 OR S4 OR S5) AND (S6 OR S7 OR S8 OR S9 OR S10 OR S11)

S11 critical interpretative synthes?s or ecological triangulation* or grounded formal theor* or metaethnograph* s or meta-interpret* or meta-narrative* or metanarrative* or meta-stud* or metasummar* or meta-synthes?s or qualitative meta-analys?s or qualitative synthes?s or textual narrative synthes?s or thematic synthes?s

S10 S8 OR S9

S9 (MH "Meta Synthesis") OR (MH "Thematic Analysis")

S8 ( S6 OR S7 ) AND (qualitative OR interpretive OR ethnograph*)

S7 (MH "Meta Analysis")

S6 (MH "Systematic Review")

S5 (MH "Altruism")

S4 (MH "Respect")

S3 (MH "Trust")

S2 (MH "Empathy") OR (MH "Caring+")

S1 (MH "Humanism") 


\section{References}

Abad-Corpa, E., Gonzalez-Gil, T., Martínez-Hernández, A., Barderas-Manchado, A. M., la CuestaBenjumea, D., Monistrol-Ruano, O., \& Mahtani-Chugani, V. (2012). Caring to achieve the maximum independence possible: a synthesis of qualitative evidence on older adults' adaptation to dependency. Journal of Clinical Nursing, 21(21-22), 3153-3169.

Andershed, B., \& Olsson, K. (2009). Review of research related to Kristen Swanson's middle-range theory of caring. Scandinavian Journal of Caring Sciences, 23(3), 598-610.

Ando, S., Clement, S., Barley, E. A., \& Thornicroft, G. (2011). The simulation of hallucinations to reduce the stigma of schizophrenia: a systematic review. Schizophrenia Research, 133(1), 8-16.

Avery, M. D., Saftner, M. A., Larson, B., \& Weinfurter, E. V. (2014). A systematic review of maternal confidence for physiologic birth: Characteristics of prenatal care and confidence measurement. Journal of Midwifery \& Women's Health, 59(6), 586-595.

Bates, M. J. (1989). The design of browsing and berrypicking techniques for the online search interface. Online review. Retrieved from https://doi.org/10.1108/eb024320 (accessed August 1, 2017).

Bearman, M., \& Dawson, P. (2013). Qualitative synthesis and systematic review in health professions education. Medical Education, 47(3), 252-260.

Berg, M. (2005). A midwifery model of care for childbearing women at high risk: genuine caring in caring for the genuine. The Journal of Perinatal Education, 14(1), 9-21.

Biddle, C., \& Schafft, K. A. (2015). Axiology and anomaly in the practice of mixed methods work: pragmatism, valuation, and the transformative paradigm. Journal of Mixed Methods Research, 9(4), 320-334.

Bondas, T., \& Hall, E. O. (2007). Challenges in approaching metasynthesis research. Qualitative Health Research, 17(1), 113-121.

Booth, A. (2016). Searching for qualitative research for inclusion in systematic reviews: a structured methodological review. Systematic reviews, 5(1), 1.

Booth, A., Harris, J., Croot, E., Springett, J., Campbell, F., \& Wilkins, E. (2013). Towards a methodology for cluster searching to provide conceptual and contextual "richness" for systematic reviews of complex interventions: case study (CLUSTER). BMC medical research methodology, 13(1), 118.

Bowers, B. B. (2002). Mothers' experiences of labor support: Exploration of qualitative research. Journal of Obstetric, Gynecologic \& Neonatal Nursing, 31(6), 742-752.

Carroll, C., \& Booth, A. (2015). Quality assessment of qualitative evidence for systematic review and synthesis: Is it meaningful, and if so, how should it be performed? Research synthesis methods, 6(2), 149-154.

Carter, S. M., \& Little, M. (2007). Justifying knowledge, justifying method, taking action: Epistemologies, methodologies, and methods in qualitative research. Qualitative Health Research, 17(10), 13161328.

Coffman, M. J. (2004). Cultural caring in nursing practice: A meta-synthesis of qualitative research. Journal of Cultural Diversity, 11(3), 100.

Cohen, J. J. (2007). Viewpoint: linking professionalism to humanism: what it means, why it matters. Academic Medicine, 82(11), 1029-1032.

Cooke, A., Smith, D., \& Booth, A. (2012). Beyond PICO the SPIDER tool for qualitative evidence synthesis. Qualitative Health Research, 22(10), 1435-1443.

Cowen, V. S., Kaufman, D., \& Schoenherr, L. (2016). A review of creative and expressive writing as a pedagogical tool in medical education. Medical Education, 50(3), 311-319.

Critical Appraisal Skills Programme (CASP). (n.d.). Retrieved from http://www.caspuk.net/criticalappraisal (accessed August 1, 2017).

Daveson, B. A., Bechinger-English, D., Bausewein, C., Simon, S. T., Harding, R., Higginson, I. J., \& Gomes on behalf of PRISMA, B. (2011). Constructing understandings of end-of-life care in Europe: a 
qualitative study involving cognitive interviewing with implications for cross-national surveys. Journal of Palliative Medicine, 14(3), 343-349.

Dixon-Woods, M., Bonas, S., Booth, A., Jones, D. R., Miller, T., Sutton, A. J., . . Young, B. (2006). How can systematic reviews incorporate qualitative research? A critical perspective. Qualitative research, 6(1), 27-44.

Dixon-Woods, M., Booth, A., \& Sutton, A. J. (2007). Synthesizing qualitative research: a review of published reports. Qualitative Research, 7(3), 375-422.

Dixon, D. M. (1996). Unifying concepts in parents' experiences with health care providers. Journal of Family Nursing, 2(2), 111-132.

Edwards, A., Pang, N., Shiu, V., \& Chan, C. (2010). Review: The understanding of spirituality and the potential role of spiritual care in end-of-life and palliative care: a meta-study of qualitative research. Palliative Medicine, 24(8), 753-770.

Egerod, I., Bergbom, I., Lindahl, B., Henricson, M., Granberg-Axell, A., \& Storli, S. L. (2015). The patient experience of intensive care: a meta-synthesis of Nordic studies. International Journal of Nursing Studies, 52(8), 1354-1361.

Ellaway, R., O'Gorman, L., Strasser, R., Marsh, D., Graves, L., Fink, P., \& Cervin, C. (2016). A critical hybrid realist-outcomes systematic review of relationships between medical education programmes and communities: BEME Guide No. 35. Medical Teacher, 38(3), 229-245.

Entwistle, V., Firnigl, D., Ryan, M., Francis, J., \& Kinghorn, P. (2012). Which experiences of health care delivery matter to service users and why? A critical interpretive synthesis and conceptual map. Journal of Health Services Research and Policy, 17(2), 70-78.

Finfgeld-Connett, D., \& Johnson, E. D. (2011). Therapeutic substance abuse treatment for incarcerated women. Clinical Nursing Research, 20(4), 462-481.

Finfgeld-Connett, D. (2005). Clarification of social support. Journal of Nursing Scholarship, 37(1), 4-9.

Finfgeld-Connett, D. (2006). Meta-synthesis of presence in nursing. Journal of Advanced Nursing, 55(6), 708-714.

Finfgeld-Connett, D. (2008). Qualitative convergence of three nursing concepts: art of nursing, presence and caring. Journal of Advanced Nursing, 63(5), 527-534.

France, E. F., Ring, N., Thomas, R., Noyes, J., Maxwell, M., \& Jepson, R. (2014). A methodological systematic review of what's wrong with meta-ethnography reporting. BMC Medical Research Methodology, 14(1), 119.

Fredriksson, L. (1999). Modes of relating in a caring conversation: a research synthesis on presence, touch and listening. Journal of Advanced Nursing, 30(5), 1167-1176.

Frost, J., Garside, R., Cooper, C., \& Britten, N. (2016). Meta-study as diagnostic: Toward content over form in qualitative synthesis. Qualitative Health Research, 26(3), 307-319.

Gillman, L., Adams, J., Kovac, R., Kilcullen, A., House, A., \& Doyle, C. (2015). Strategies to promote coping and resilience in oncology and palliative care nurses caring for adult patients with malignancy: a comprehensive systematic review. JBI Database of Systematic Reviews and Implementation Reports, 13(5), 131-204.

Glassick, C. E., Huber, M. T., Maeroff, G. I., \& Boyer, E. (1997). Scholarship assessed (Vol. 9): San Francisco: Jossey-Bass.

Goldberg, J. L. (2008). Humanism or professionalism? The white coat ceremony and medical education. Academic Medicine, 83(8), 715-722.

Gordon, J., Sheppard, L. A., \& Anaf, S. (2010). The patient experience in the emergency department: A systematic synthesis of qualitative research. International Emergency Nursing, 18(2), 80-88.

Graneheim, U. H., Johansson, A., \& Lindgren, B. M. (2014). Family caregivers' experiences of relinquishing the care of a person with dementia to a nursing home: Insights from a metaethnographic study. Scandinavian Journal of Caring Sciences, 28(2), 215-224.

Hannes, K. (2011). Chapter 4: Critical appraisal of qualitative research. In B. A. In: Noyes J, Hannes K, Harden A, Harris J, Lewin S, Lockwood C, (Ed.), Supplementary Guidance for Inclusion of 
Qualitative Research in Cochrane Systematic Reviews of Interventions. Version 1 (updated August 2011): Cochrane Collaboration Qualitative Methods Group.

Hannes, K., Booth, A., Harris, J., \& Noyes, J. (2013). Celebrating methodological challenges and changes: reflecting on the emergence and importance of the role of qualitative evidence in Cochrane reviews. Systematic reviews, 2(1), 84.

Hannes, K., \& Macaitis, K. (2012). A move to more systematic and transparent approaches in qualitative evidence synthesis: update on a review of published papers. Qualitative Research, 12(4), 402442.

Harrison, T. M. (2010). Family-centered pediatric nursing care: State of the science. Journal of Pediatric Nursing, 25(5), 335-343.

Hemmerdinger, J. M., Stoddart, S. D., \& Lilford, R. J. (2007). A systematic review of tests of empathy in medicine. BMC Medical Education, 7(1), 24.

Heron, J., \& Reason, P. (1997). A participatory inquiry paradigm. Qualitative inquiry, 3(3), 274-294.

Hunter, L. P. (2002). Being with woman: a guiding concept for the care of laboring women. Journal of Obstetric, Gynecologic, and Neonatal Nursing, 31(6), 650-657.

Johnston, B., Larkin, P., Connolly, M., Barry, C., Narayanasamy, M., Östlund, U., \& Mcllfatrick, S. (2015). Dignity-conserving care in palliative care settings: an integrative review. Journal of Clinical Nursing, 24(13-14), 1743-1772.

Killick, C., \& Taylor, B. J. (2009). Professional decision making on elder abuse: systematic narrative review. Journal of Elder Abuse \& Neglect, 21(3), 211-238.

Kitson, A., Marshall, A., Bassett, K., \& Zeitz, K. (2013). What are the core elements of patient-centred care? A narrative review and synthesis of the literature from health policy, medicine and nursing. Journal of Advanced Nursing, 69(1), 4-15.

Kogan, A. C., Wilber, K., \& Mosqueda, L. (2016). Person-Centered Care for Older Adults with Chronic Conditions and Functional Impairment: A Systematic Literature Review. Journal of the American Geriatrics Society, 64(1), e1-e7.

Kung, J., Chiappelli, F., Cajulis, O. O., Avezova, R., Kossan, G., Chew, L., \& Maida, C. A. (2010). From systematic reviews to clinical recommendations for evidence-based health care: validation of revised assessment of multiple systematic reviews (R-AMSTAR) for grading of clinical relevance. The open dentistry journal, 4(1).

Ljungberg, A., Denhov, A., \& Topor, A. (2015). The art of helpful relationships with professionals: A metaethnography of the perspective of persons with severe mental illness. Psychiatric Quarterly, 86(4), 471-495.

Martimianakis, M. A. T., Michalec, B., Lam, J., Cartmill, C., Taylor, J. S., \& Hafferty, F. W. (2015). Humanism, the hidden curriculum, and educational reform: A scoping review and thematic analysis. Academic Medicine, 90(11), S5-S13.

Megnin-Viggars, O., Symington, I., Howard, L. M., \& Pilling, S. (2015). Experience of care for mental health problems in the antenatal or postnatal period for women in the UK: a systematic review and meta-synthesis of qualitative research. Archives of Women's Mental Health, 18(6), 745-759.

Melin-Johansson, C., Axelsson, I., Grundberg, M. J., \& Hallqvist, F. (2014). When a Child Dies: Parents' Experiences of Palliative Care-An Integrative Literature Review. Journal of Pediatric Nursing, 29(6), 660-669.

Mills, T., Ricklesford, C., Cooke, A., Heazell, A., Whitworth, M., \& Lavender, T. (2014). Parents' experiences and expectations of care in pregnancy after stillbirth or neonatal death: a metasynthesis. BJOG: An International Journal of Obstetrics and Gynaecology, 121(8), 943-950.

Moos, I., \& Björn, A. (2006). Use of the life story in the institutional care of people with dementia: a review of intervention studies. Ageing and Society, 26(03), 431-454.

Murray, B., \& McCrone, S. (2015). An integrative review of promoting trust in the patient-primary care provider relationship. Journal of Advanced Nursing, 71(1), 3-23. 
Okello, D. R., \& Gilson, L. (2015). Exploring the influence of trust relationships on motivation in the health sector: a systematic review. Human Resources for Health, 13(1), 16.

Papaioannou, D., Sutton, A., Carroll, C., Booth, A., \& Wong, R. (2010). Literature searching for social science systematic reviews: consideration of a range of search techniques. Health Information \& Libraries Journal, 27(2), 114-122.

Paterson, B. L., Canam, C., Thorne, S., \& Jillings, C. (2001). Meta-study of qualitative health research: A practical guide to meta-analysis and meta-synthesis (Vol. 3): Sage.

Pearce, G., Pinnock, H., Epiphaniou, E., Parke, H. L., Heavey, E., Griffiths, C. J., . . Taylor, S. J. (2015). Experiences of self-management support following a stroke: a meta-review of qualitative systematic reviews. PloS One, 10(12), e0141803.

Pedersen, R. (2009). Empirical research on empathy in medicine-A critical review. Patient Education and Counseling, 76(3), 307-322.

Peters, M. D., Lisy, K., Riitano, D., Jordan, Z., \& Aromataris, E. (2015). Caring for families experiencing stillbirth: evidence-based guidance for maternity care providers. Women and Birth, 28(4), 272278.

Phillips-Salimi, C. R., Haase, J. E., \& Kooken, W. C. (2012). Connectedness in the context of patientprovider relationships: A concept analysis. Journal of Advanced Nursing, 68(1), 230-245.

Piderman, K. M., Kung, S., Jenkins, S. M., Euerle, T. T., Yoder, T. J., Kwete, G. M., \& Lapid, M. I. (2015). Respecting the spiritual side of advanced cancer care: A systematic review. Current Oncology Reports, 17(2), 1-9.

Piira, T., Sugiura, T., Champion, G., Donnelly, N., \& Cole, A. (2005). The role of parental presence in the context of children's medical procedures: a systematic review. Child: Care, Health and Development, 31(2), 233-243.

Pole, D. (1961). Conditions of Rational Inquiry: A Study in the Philosophy of Value: University of London, Athlone Press.

Polit, D. F., \& Beck, C. T. (2008). Nursing research: Generating and assessing evidence for nursing practice: Lippincott Williams \& Wilkins.

Ridd, M., Shaw, A., Lewis, G., \& Salisbury, C. (2009). The patient-doctor relationship: a synthesis of the qualitative literature on patients' perspectives. British Journal of General Practice, 59(561), e116-e133.

Rogers, J. C., \& Coutts, L. (2000). Do students' attitudes during preclinical years predict their humanism as clerkship students? Academic Medicine, 75(10), S74-S77.

Rowe, J. (2012). Great expectations: a systematic review of the literature on the role of family carers in severe mental illness, and their relationships and engagement with professionals. Journal of Psychiatric and Mental Health Nursing, 19(1), 70-82.

Rudolfsson, G., \& Berggren, I. (2012). Nursing students' perspectives on the patient and the impact of the nursing culture: a meta-synthesis. Journal of Nursing Management, 20(6), 771-781.

Schmied, V., Beake, S., Sheehan, A., McCourt, C., \& Dykes, F. (2011). Women's Perceptions and Experiences of Breastfeeding Support: A Metasynthesis. Birth, 38(1), 49-60.

Seal, K., Murray, C. D., \& Seddon, L. (2015). The experience of being an informal "carer" for a person with cancer: A meta-synthesis of qualitative studies. Palliative and Supportive Care, 13(03), 493504.

Smajdor, A., Stöckl, A., \& Salter, C. (2011). The limits of empathy: problems in medical education and practice. Journal of Medical Ethics, 37(6), 380-383.

Strandberg, T., Eklund, J., \& Manthorpe, J. (2012). Promoting empathy in social care for older people. Working with Older People, 16(3), 101-110.

Sulzer, S. H., Feinstein, N. W., \& Wendland, C. L. (2016). Assessing empathy development in medical education: a systematic review. Medical Education, 50(3), 300-310.

Swift, K., Sayal, K., \& Hollis, C. (2014). ADHD and transitions to adult mental health services: a scoping review. Child: Care, Health and Development, 40(6), 775-786. 
Tay, L. H., Hegney, D., \& Ang, E. (2011). Factors affecting effective communication between registered nurses and adult cancer patients in an inpatient setting: a systematic review. International Journal of Evidence-Based Healthcare, 9(2), 151-164.

The Joanna Briggs Institute. (2014). The Joanna Briggs Institute Reviewers' Manual: 2014 edition. Retrieved from https://ioannabriggs.org/assets/docs/sumari/ReviewersManual-2014.pdf (accessed August 1, 2017).

The Joanna Briggs Institute. (2017). Joanna Briggs Institute Reviewer's Manual. https://reviewersmanual.joannabriggs.org/ (accessed August 1, 2017).

Thomas, J., \& Harden, A. (2008). Methods for the thematic synthesis of qualitative research in systematic reviews. BMC Medical Research Methodology, 8(1), 45.

Thorne, S., Jensen, L., Kearney, M. H., Noblit, G., \& Sandelowski, M. (2004). Qualitative metasynthesis: reflections on methodological orientation and ideological agenda. Qualitative Health Research, 14(10), 1342-1365.

Tong, A., Cheung, K. L., Nair, S. S., Tamura, M. K., Craig, J. C., \& Winkelmayer, W. C. (2014). Thematic synthesis of qualitative studies on patient and caregiver perspectives on end-of-life care in CKD. American Journal of Kidney Diseases, 63(6), 913-927.

Tong, A., Sainsbury, P., \& Craig, J. (2007). Consolidated criteria for reporting qualitative research (COREQ): a 32-item checklist for interviews and focus groups. International Journal for Quality in Health Care, 19(6), 349-357.

Tranvåg, O., Petersen, K. A., \& Nåden, D. (2013). Dignity-preserving dementia care: a metasynthesis. Nursing Ethics, 20(8), 861-880.

U.S. National Library of Medicine. (2015). Humanism (MeSH) Descriptor Data 2017. Retrieved from https://meshb.nlm.nih.gov/record/ui?ui=D006808 (accessed August 1, 2017)

Varpio, L., Ajjawi, R., Monrouxe, L. V., O'brien, B. C., \& Rees, C. E. (2017). Shedding the cobra effect: problematising thematic emergence, triangulation, saturation and member checking. Medical Education, 51(1), 40-50.

Wikberg, A., \& Bondas, T. (2010). A patient perspective in research on intercultural caring in maternity care: A meta-ethnography. International Journal of Qualitative Studies on Health and Wellbeing, 5(1).

Zolnierek, C. D. (2014). An integrative review of knowing the patient. Journal of Nursing Scholarship, 46(1), 3-10. 
Considering axiological integrity: a methodological analysis

Figure 1. Search terms used to identify papers on humanism examined by qualitative evidence synthesis

Qualitative Review
Critical Interpretative Synthesis
Ecological triangulation
Grounded formal theory
Meta-analysis
Meta-ethnography
Meta-interpretation
Meta-narrative
Meta-study
Meta-summary
Meta-synthesis
Qualitative meta-analysis
Qualitative synthesis
Realist review
Systematic review
Textual narrative synthesis
Thematic synthesis

\begin{tabular}{|c|c|}
\hline Healthcare & Humanism \\
\hline Delivery of healthcare & Altruism \\
\hline Health Occupation & Caring \\
\hline Health services & Compassion \\
\hline Organizational culture & Empathy \\
\hline \multirow{5}{*}{$\begin{array}{l}\text { Professional-patient } \\
\text { relations }\end{array}$} & Humane \\
\hline & Kindness \\
\hline & Presence \\
\hline & Respect \\
\hline & Trust \\
\hline
\end{tabular}


Figure 2. PRISMA flow diagram for Qualitative evidence for synthesis studies on humanism

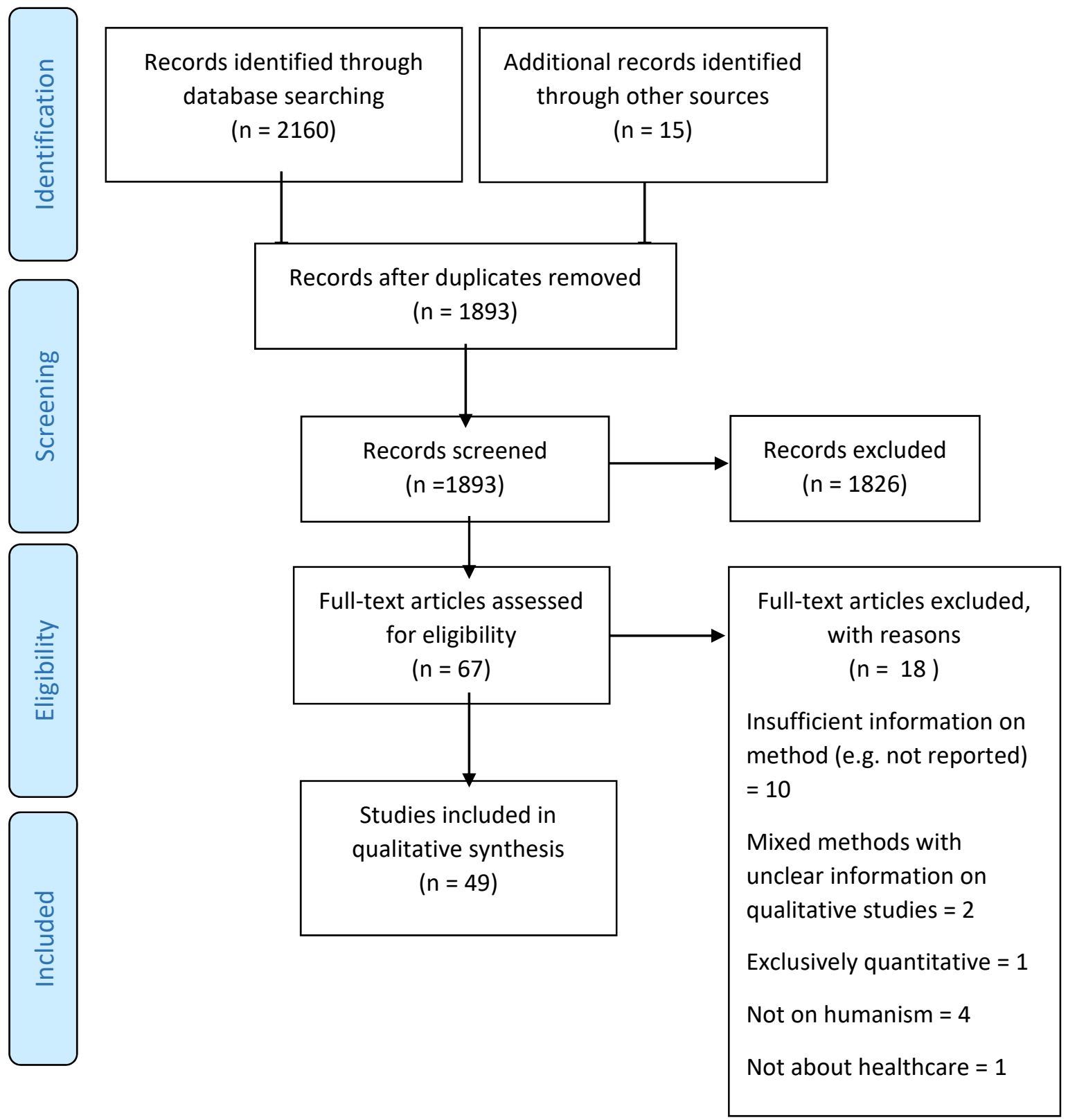




\section{Considering axiological integrity: a methodological analysis}

\section{Table 1. Analytical components examined in the data}

\section{Descriptive data}

- year, journal, where review conducted, author(s) profession(s), study aims, number of studies included in the review

Meta-method (review of methodological characteristics used)

- Type of data examined in the review a) qualitative or mixed methods b) empirical studies, editorials, commentaries, policy documents

- Search: evaluation of search strategy, comments on strengths and weaknesses

- Quality appraisal: a) if performed or not, name of tool b) justification and consequence of use c) alignment of approach to quality appraisal and epistemological approach of review

- Stated review methodology, alignment between stated methodology and research findings

Meta-analysis (review of analytic and synthetic process of reviews)

- Data extraction: evaluation of data extraction, strengths and weaknesses

- Coherence between data extraction, coding, categorization and findings

- Reproducibility (or acknowledgement of this as an issue) between data and findings

- Evidence of author reflexivity

- Discussion and interpretation of findings in relation to research question

- Examination of findings, if and how they extended beyond the primary studies, if the implications are supported by the study

Meta-theory (if and how theory contributed to the review process)

- If theory was identified, if theory was used to problematize the review or justify methodological approach, how findings and theory were related (or not), if theoretical development was an output of the review

- Relation of theory to the bigger picture - social, historical, cultural, political context

- Examination of epistemological perspective expressed in the conduct of the review 
Considering axiological integrity: a methodological analysis

Meta-synthesis

- Examined strengths and limitations of review methodologies as applied to the study of humanism

- Critical interpretation of coherence between study question, methodology and epistemology

- Uncovering assumptions within the conduct of QES reviews in the field of clinical humanism 
Table 2. Epistemological Positions of Studies reviewed (Barnett-Page and Thomas, 2009)

Position

Definition

Subjective idealism

There is no single shared reality independent of multiple

alternative human constructions

Objective idealism

There is a world of collectively shared understandings

Critical realism

Scientific realism

Naïve realism
Knowledge of reality is mediated by our perceptions and beliefs

It is possible for knowledge to approximate closely an external 'reality'

Maintains that reality exists independently of human constructions and can be known directly.

\section{Number}

of studies
(Kitson, Marshall, Bassett, \& Zeitz, 2013)

(Entwistle et al., 2012)

(Andershed \& Olsson, 2009; Coffman, 2004; Daveson et al., 2011; Dixon, 1996; Edwards, Pang, Shiu, \& Chan, 2010; Egerod et al., 2015; Finfgeld-

Connett \& Johnson, 2011; Finfgeld-Connett, 2008; Fredriksson, 1999; Gordon, Sheppard, \& Anaf, 2010; Ljungberg, Denhov, \& Topor, 2015; Peters, Lisy, Riitano, Jordan, \& Aromataris, 2015; Rudolfsson \&

Berggren, 2012; Strandberg, Eklund, \& Manthorpe, 2012; Wikberg \& Bondas, 2010)

(Ando, Clement, Barley, \& Thornicroft, 2011; Bowers, 2002; FinfgeldConnett, 2005, 2006, 2008; Hunter, 2002; Johnston et al., 2015; MelinJohansson, Axelsson, Grundberg, \& Hallqvist, 2014; Moos \& Björn, 2006; Murray \& McCrone, 2015; Okello \& Gilson, 2015; Piderman et al., 2015 Rowe, 2012; Schmied, Beake, Sheehan, McCourt, \& Dykes, 2011; Seal, Murray, \& Seddon, 2015; Tong et al., 2014; Tranvåg, Petersen, \& Nåden, 2013; Zolnierek, 2014);(Phillips-Salimi, Haase, \& Kooken, 2012);(Ridd Shaw, Lewis, \& Salisbury, 2009)

(Abad-Corpa et al., 2012; Gillman et al., 2015; Harrison, 2010; Kogan Wilber, \& Mosqueda, 2016; Megnin-Viggars, Symington, Howard, \& Pilling, 2015; Mills et al., 2014; Piira, Sugiura, Champion, Donnelly, \& Cole, 2005; Swift, Sayal, \& Hollis, 2014; Tay, Hegney, \& Ang, 2011)

(Avery, Saftner, Larson, \& Weinfurter, 2014; Berg, 2005; Graneheim Johansson, \& Lindgren, 2014; Killick \& Taylor, 2009) 
Considering axiological integrity: a methodological analysis 